\title{
Impacts of Future Grassland Changes on Surface Climate in Mongolia
}

\author{
Fan Zhang, ${ }^{1}$ Xing Li, ${ }^{1}$ Weimin Wang, ${ }^{2}$ Xinli Ke, ${ }^{3}$ and Qingling Shi ${ }^{4,5}$ \\ ${ }^{1}$ School of Mathematics and Physics, China University of Geosciences, Wuhan 430074, China \\ ${ }^{2}$ Shenzhen Environmental Monitoring Center, Shenzhen, Guangdong 518049, China \\ ${ }^{3}$ College of Land Management, Huazhong Agricultural University, Wuhan 430079, China \\ ${ }^{4}$ Institute of Geographic Sciences and Natural Resources Research, Chinese Academy of Sciences, Beijing 100101, China \\ ${ }^{5}$ Center for Chinese Agricultural Policy, Chinese Academy of Sciences, Beijing 100101, China
}

Correspondence should be addressed to Fan Zhang; zhangf.ccap@igsnrr.ac.cn

Received 18 July 2013; Revised 25 September 2013; Accepted 18 October 2013

Academic Editor: Xiangzheng Deng

Copyright (C) 2013 Fan Zhang et al. This is an open access article distributed under the Creative Commons Attribution License, which permits unrestricted use, distribution, and reproduction in any medium, provided the original work is properly cited.

Climate change caused by land use/cover change (LUCC) is becoming a hot topic in current global change, especially the changes caused by the grassland degradation. In this paper, based on the baseline underlying surface data of 1993, the predicted underlying surface data which can be derived through overlaying the grassland degradation information to the map of baseline underlying surface, and the atmospheric forcing data of RCP 6.0 from CMIP5, climatological changes caused by future grassland changes for the years 2010-2020 and 2040-2050 with the Weather Research Forecast model (WRF) are simulated. The model-based analysis shows that future grassland degradation will significantly result in regional climate change. The grassland degradation in future could lead to an increasing trend of temperature in most areas and corresponding change range of the annual average temperature of $-0.1^{\circ} \mathrm{C}-$ $0.4^{\circ} \mathrm{C}$, and it will cause a decreasing trend of precipitation and corresponding change range of the annual average precipitation of $10 \mathrm{~mm}-50 \mathrm{~mm}$. This study identifies lines of evidence for effects of future grassland degradation on regional climate in Mongolia which provides meaningful decision-making information for the development and strategy plan making in Mongolia.

\section{Introduction}

During the last millennium, human beings have changed natural ecosystems, such as converting forest lands and grasslands into croplands, pastures, and bare soil [1]. The land use and cover changes (LUCC), in which the human activities play a dominant role, interact with the environment and have significant effects on the ecosystems at the local, regional, and global scales and consequently directly or indirectly exert great influence on the global climate changes [2-5]. Anthropogenic climate changes gradually attracted worldwide concerns in recent years. The interaction mechanisms between land surface processes and climatic conditions have been increasingly investigated and modeled. These LUCC will continue to exert impacts on the climate in the future. The conversion from one land use/cover type to another is more often than an impermanent change. Thus any impact on the climate due to this change would not be short lived; rather it would be a long term effect having lasting effects on the climate [6]. Significant global warming occurred in the twentieth century and especially in the most recent decades. Global mean surface air temperature increased with a rate of $0.07^{\circ} \mathrm{C}$ per decade from 1906 to 2005 [7]. It seems that the magnitude of importance of LUCC on future climate can only be determined by knowing and understanding how certain land conversions directly impact on climate on regional scales.

It has long been known that climate change and LUCC influenced each other. The land use changes caused by human activities such as deforestation[8-11], grassland degradation $[12,13]$, agriculture practice $[14,15]$, and urbanization [16-18] all have some influences on the climate [19], while at present most of the previous researches are aimed at the influences of climate change on LUCC [20-22]. As to Mongolia, what was concerned most was the grassland change caused by climate change, while the studies that focused on the effects of LUCC 
on climate, especially the effect of grassland change on climate in Mongolia, were not that much, since human activities are getting more and more active, which made LUCC influence the climate system at various temporal and spatial scales [23-25]. For example, the deforestation may lead to the temperature decrease in the tropic zone, while it may lead to the regional temperature decrease in the Frigid Zone [26]. It was turned out that the human activities may account for $90 \%$ of the reasons for the global warming according to the fourth assessment report of Intergovernmental Panel on Climate Change (IPCC AR4), and $1 / 3$ of the global $\mathrm{CO}_{2}$ increase was caused by land use change since the 1750s. It has been known that grassland can feed for livestock; at the same time, it could adjust the ecosystem and the climate system with its ecosystem service function. So the change of grassland and its effect on climate system are becoming a significant and hot issue on global change in recent years. Previous studies showed that increase of grassland since preindustrial times has caused an overall warming trend in both mean and extreme temperatures which is detectable in the observed temperature changes $[27,28]$. The warming in both mean and extreme temperatures due to anthropogenic forcing other than land use is detected in all cases, whereas the relatively weak effect of natural climatic forcing is not detected in any research.

The grassland is an important land use type that plays an important role in the ecosystem services supply. It is of great significance to the grassland management to determine the changing trend of grassland productivity and its response to climate change [29]. It can be seen that previous studies are all focused on the effects of LUCC on climate but we can rarely find the study about the influences of grassland change on climate especially in Mongolia. Grassland is an important land cover type, and the change of grassland area would have a notable influence on the regional climate change. The impacts of LUCC on climate can be divided into two major categories: biogeochemical and biogeophysical. Biogeochemical processes can easily affect the regional climate through changing the chemical composition of the atmosphere. Biogeophysical processes affect the physical parameters that determine the amount of solar energy that is absorbed by the Earth's surface, as well as how this energy is distributed at the Earth's surface. The most important one of these parameters which is considered most often with respect to climate is albedo. The albedo of a region with high-quality grassland is lower than that of a desert. Changing the albedo by converting the land use and cover types, the amount of energy absorbed would change and reflect out of the region, and then the local climate would be affected. In addition, the land use activities also have significant effects on the characteristics of regional climate system, for example, the temperature, evapotranspiration, precipitation, atmospheric pressure, and, especially, the temperature and precipitation $[30,31]$. The recent researches suggest that the LUCC may affect the extremes in temperature and precipitation [32]. Therefore, in this study, we will present some lines of evidence for future grassland change effect on regional climate based on simulations of precipitation and temperature in Mongolia. And the result would contribute to reasonable utilization of grassland and provide some theoretical and scientific support for the development and the strategy plan making in Mongolia.

\section{Case Study Area}

Mongolia is located in the middle of Asia with bordering Russia to the north and the Inner Mongolia region of China to the south, east, and west. It is the second-largest inland country all over the world with total area of 1.56 million $\mathrm{km}^{2}$. And its national territorial area ranks the 18th in the world. Most of the country's area is covered by steppes which accounting for more than $70 \%$ of the national area (Figure 1). Mongolia is located in the Mongolian Plateau; its west, north, and middle are mountainous region; its eastern part is hills and plains and the southern part is Gobi desert. Mongolia is far away from the coast and has obvious inland climate characteristics. There is a large difference of the temperature daily and in seasons. The winter is cold and long and its summer is warm and short. According to the dates from Mongolia Meteorological Administration from 1960 to 2006, in northern Mongolia, the temperature is relatively low with annual average temperature of $-5^{\circ} \mathrm{C}$ or even much lower; in the southern part of plain the annual average temperature is $4^{\circ} \mathrm{C}$ [33]. The hottest month is July, the average temperature in the areas of Altai County, Hangay County, Hövsgöl County, and Hentiy Nuruu is $10^{\circ} \mathrm{C}-15^{\circ} \mathrm{C}$. The temperature in Gobi desert and the eastern plains of Mongolia is more than $20^{\circ} \mathrm{C}$ [34]. And average annual precipitation in Mongolia is 200-300 mm from 1980 to 2006 [35]. Global warming is a "natural phenomenon." There has been a significant increase in global temperature since 1980s. In the recent 20 years, the global average temperature has risen by $0.74^{\circ} \mathrm{C}$, while average temperature of Mongolia rose by $1.5^{\circ} \mathrm{C}$ to $2.5^{\circ} \mathrm{C}$, which is two or three times the world average level [36]. The precipitation in Mongolia is not too much in the whole year. Storm and drought are the two main nature disasters for the agriculture and animal husbandry production.

The pillar industry in Mongolia's national economy is always stock farming. And approximately $30 \%$ of the population is nomadic or seminomadic. So grassland is quite important in Mongolia. Revealing the effects of grassland change on climate is of global importance in such a typical region. Its grassland is mainly divided into forest grassland, typical grassland, mountain grassland, desert grassland, and desert. Since the 1960s, due to overgrazing, herds imbalance, the excessive use of pastures, and the effects of global warming, the decrements of species in forest grassland, typical grassland, mountain grassland, desert grassland, and desert are $50 \%, 44.73 \%, 30.3 \%, 23.8 \%$, and $26.7 \%$, respectively. The forage grass of high quality was gradually recessed or replaced by inferior plants (bushes, shrubs, etc.) [37]. Many species of plants decreased greatly and forage value declined year by year. From 1961 to 2006, the rates of pasture production decline rate in forest grassland, typical grassland, mountain grassland, desert grassland, and desert are 40.54\%, 52.17\%, $39.28 \%, 33.33 \%$, and $39.28 \%$, respectively [33]. The above studies have shown that the situation of Mongolia's grassland degradation is serious and widespread deterioration of the 


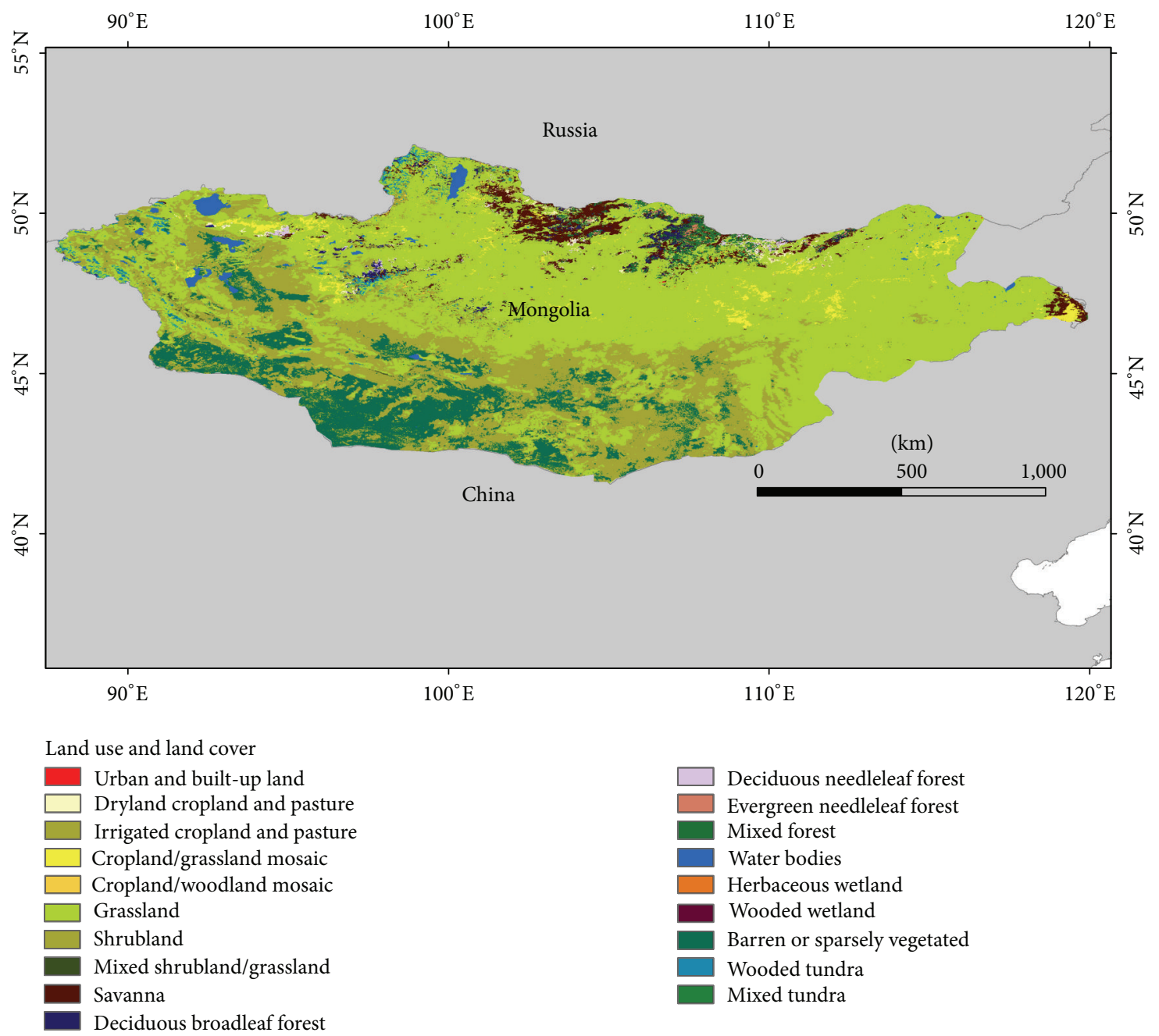

FIgURE 1: Land use and land cover of Mongolia in 1993.

pastures may lead to the increase of carbon dioxide and other greenhouse gases, thus making the temperature rise in Mongolia and the temperature rise will also cause the precipitation redistribution, make natural ecosystem out of balance, and even threaten the human food supply and living environment.

\section{Data and Methodology}

3.1. Underlying Surface Data and Atmospheric Forcing Data. There are two types of input data in WRF model, the underlying surface data and atmospheric forcing data. An advanced very high resolution radiometer (AVHRR) grid data of $1 \mathrm{~km}$ $\times 1 \mathrm{~km}$ of the United States Geological Survey's (USGS) classification system spanning a 12-month period (April 1992-March 1993, henceforth, 1993) was used as the baseline underlying surface data in this study. And the predicted land use and cover grid data of $0.5^{\circ} \times 0.5^{\circ}$ from 2010 to 2050 are derived from the database of Representative Concentration Pathway (RCP) 6.0. This database is developed by the Asia-Pacific Integrated Model (AIM) modeling team at the National Institute for Environmental Studies (NIES), Japan.
To investigate the effects of future grassland degradation on climate, we only used the grassland degradation information of the database, though change information of all kinds of land use and cover is available. Supposing that other types of land use and cover are constant, the new grassland area pixels derived from the database of RCP 6.0 were overlaid to the map of baseline underlying surface. Consequently, both of these two major underlying surface data were transformed to grid data of $50 \mathrm{~km} \times 50 \mathrm{~km}$ by resampling. The fifth phase of the Coupled Model Intercomparison Project (CMIP5) produces a state-of-the-art multimodel dataset designed to advance our knowledge of climate variability and climate change. It provides projections of future climate change on two time scales, near term and long term. Model output of the latter of RCP 6.0 such as air temperature, specific humidity, sea level pressure, eastward wind, northward wind, and geopotential height from 2010 to 2050 was used as the atmospheric forcing dataset of WRF model.

3.2. Weather Research Forecast (WRF) Model. The WRF model is a state-of-the-art atmospheric simulation system 
based on the Fifth-Generation Penn State/NCAR Mesoscale Model (MM5) and assimilation system was developed by some scientists and was used in many different institutes [38], such as the National Center for Atmospheric Research (NCAR) and the Air Force Weather Agency (AFWA). They thought that the WRF project would be a multi-institutional effort to develop an advanced mesoscale forecast and data assimilation system that would be accurate, efficient, and scalable across a range of scales and over a host of computer platforms. A lot of previous researches have showed that the WRF is a good model to simulate the climate change in future and it has been widely used all over the world $[39,40]$. Two dynamical core versions of WRF were developed in the process of application, the Advanced Research WRF (ARW), and the WRF-NMM (NMM). The former one was used to investigate the change of temperature and precipitation driven by future degradation of grassland in this study.

3.3. Experimental Design. The WRF model based on the Eulerian mass solver was used to investigate the temperature and precipitation changes driven by future grassland degradation in this study. Two sets of tests (control test and simulated test) were designed; the baseline underlying surface and predicted underlying surface were used in the above two tests, respectively. Simulation from 2010 to 2050 with a constant underlying surface (the pattern of grassland as well as other land use and cover types in the study area is fixed to that of 1993, namely, baseline underlying surface) was implemented first, whose results are regarded as baseline. Then supposing other types of land use and cover constant, the new grassland area pixels derived from the database of RCP 6.0 were overlaid to the map of baseline underlying surface; finally the predicted underlying surfaces of 2010 and 2040 were obtained. Consequently, two major underlying surface data, baseline underlying surface data directly derived from AVHRR data of 1993 and predicted underlying surface data by overlaying the grassland degradation information to the map of baseline underlying surface, were obtained. The effects of future grassland degradation on climate can be measured by the difference of the simulated results with predicted underlying surface and baseline underlying surface. Consider the following:

$$
R_{i}=C_{i}-S_{i},
$$

where $R$ is the effects of future grassland degradation on climate, $i$ refers to average of annual and monthly temperatures and average of annual and monthly precipitations, and $C$ and $S$ are the simulated results of WRF model with predicted underlying surface and baseline underlying surface, respectively.

\section{Results}

The average effects of grassland degradation on temperature and precipitation for each period of 2010-2020 and 20402050 were simulated. In the simulation of two periods, the baseline underlying surface data and predicted underlying surface data were used. Concretely, the temperature and precipitation of each period of 2010-2020 and 2040-2050 with baseline underlying surface were obtained first. And then the simulation of temperature and precipitation of two periods of 2010-2020 and 2040-2050 were continuously implemented by using the predicted underlying surface of 2010, 2040, respectively. As described above, the effects of future grassland degradation on climate were measured by the difference of the simulated results with baseline and predicted underlying surfaces, which can also reduce the simulated bias induced by discontinuous simulation. The original simulated results were hourly and aggregated into average annual data and average monthly data.

4.1. Effects on the Annual Average Temperature. The grassland is an important land use type that plays an important role in the ecosystem services supply in China. It is of great significance to the grassland management to determine the changing trend of grassland productivity and its response to climate change. The simulated results show that there would be an upward trend of annual average temperature with an increment of $0.1^{\circ} \mathrm{C}-0.3^{\circ} \mathrm{C}$ during 2010-2020 (Figure 2). In addition, the simulated results indicate that the annual average temperature shows a trend of fluctuation; the effects on temperature decrease gradually from west to east and climb up first then decline step by step from north to south. The annual average temperature changes significantly in the northwest of Mongolia in which grassland distributes the most; the temperature increased by $0.3^{\circ} \mathrm{C}$ and was higher than other regions. Besides, in a small area near the sea in the northeast, the temperature shows a trend of decline; it fell by $0.1^{\circ} \mathrm{C}$ approximately. At the same time, we found that the areas which experience the most serious grassland degradation are mainly distributed in Alli county, Ada Chad's county, and Altay city. Meanwhile the change of annual average temperature of these areas happens to be the most obvious; it indicates that the grassland degradation has a great influence on the local temperature change in Mongolia.

It fully illustrates that grassland plays an important role in regulating temperature. In order to predict the trend of future temperature in Mongolia, we use the same method to simulate the effects of grassland degradation on the average annual temperature from 2040 to 2050; the simulated result showed that there would be a upward trend of annual average temperature with an increment of $0.1-0.4^{\circ} \mathrm{C}$ during $2040-$ 2050 (Figure 3 ). The effects of temperature decrease gradually from west to east and climb up first then decline step by step from north to south. Compared with the simulated result of 2010-2020, it can be seen clearly from Figure 3 that the annual average temperature rising areas increased significantly and the areas are mainly concentrated in northwestern and central regions of Mongolia; the rising of annual average temperature was about $0.1^{\circ} \mathrm{C}$. Besides, the temperature decreases by about $0.1^{\circ} \mathrm{C}$ in some areas of southwestern and eastern regions of Mongolia. In summary, as a grassland dominated country, grassland plays an important role in regulating the climate; the impacts of future grassland changes on climate should be concerned highly in Mongolia.

4.2. Effects on the Annual Average Precipitation. The degradation of grassland leads to significant change of the spatial 


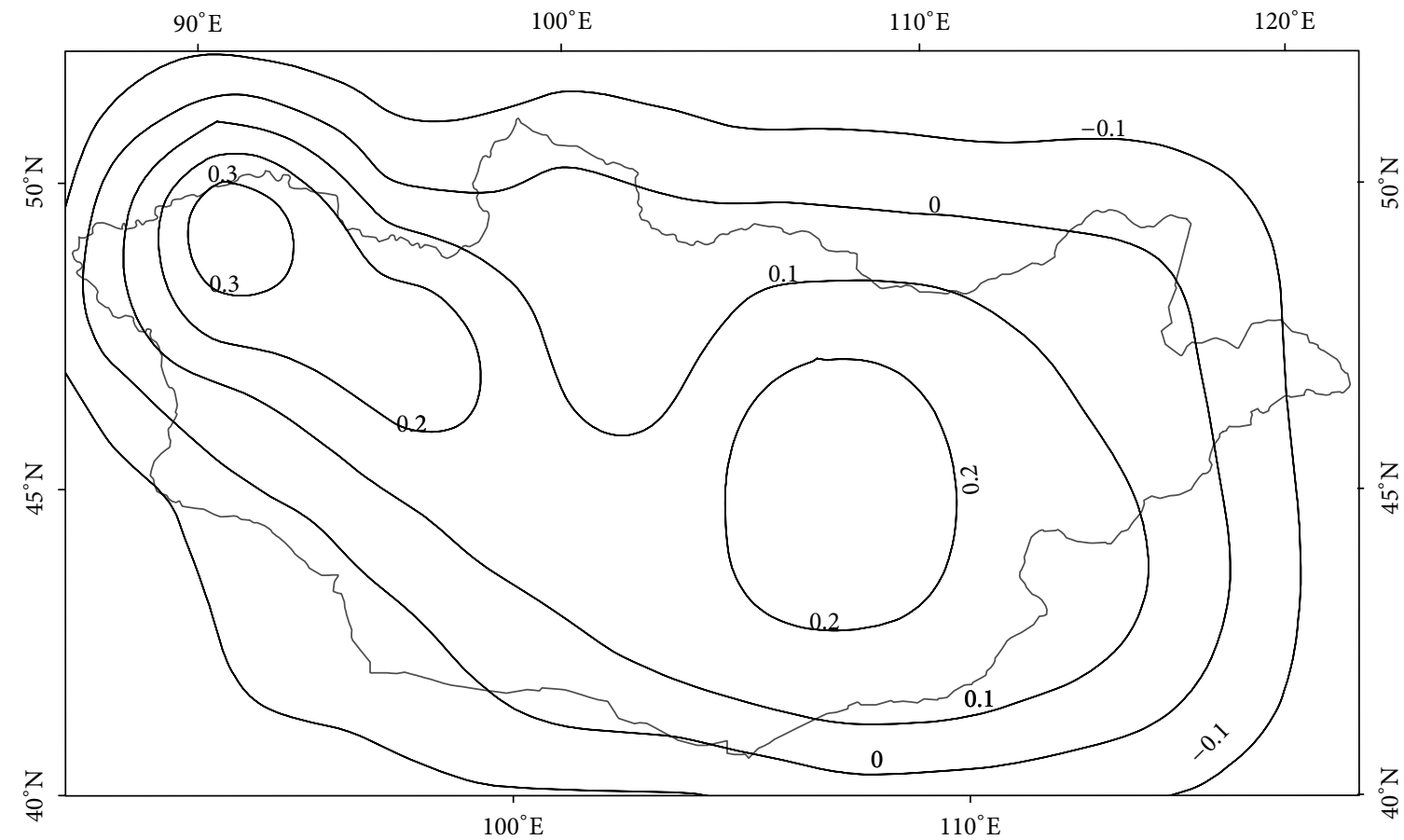

FIGURE 2: Effects of future grassland degradation on average annual temperature between years 2010 and 2020 (measured in degree Celsius) in Mongolia.

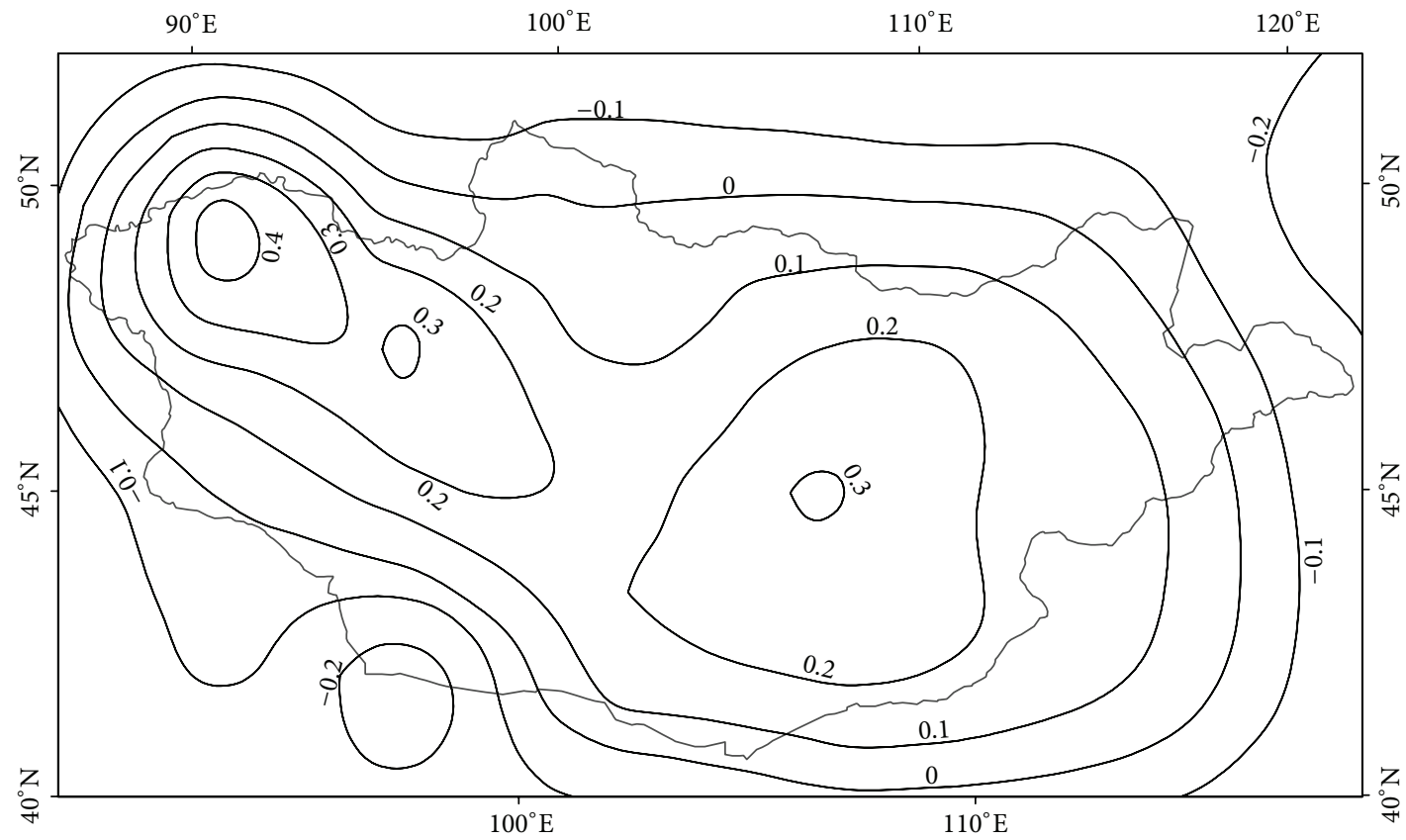

FIGURE 3: Effects of future grassland degradation on average annual temperature between years 2040 and 2050 (measured in degree Celsius) in Mongolia.

pattern of the annual average precipitation in Mongolia. The simulated result during 2010-2020 indicates that the degradation of grassland will make the annual average precipitation in the northwestern and eastern parts of Mongolia decrease by more than $40 \mathrm{~mm}$ (Figure 4). Besides, the annual average precipitation in the central part of Mongolia will also decrease by more than $20 \mathrm{~mm}$. However, the degradation of grassland will make the overall annual average precipitation in the simulated area decrease by $25 \mathrm{~mm}$.

In comparison, the simulated results during 2040-2050 indicated that the overall effects of the grassland degradation on the annual average precipitation are as significant as 


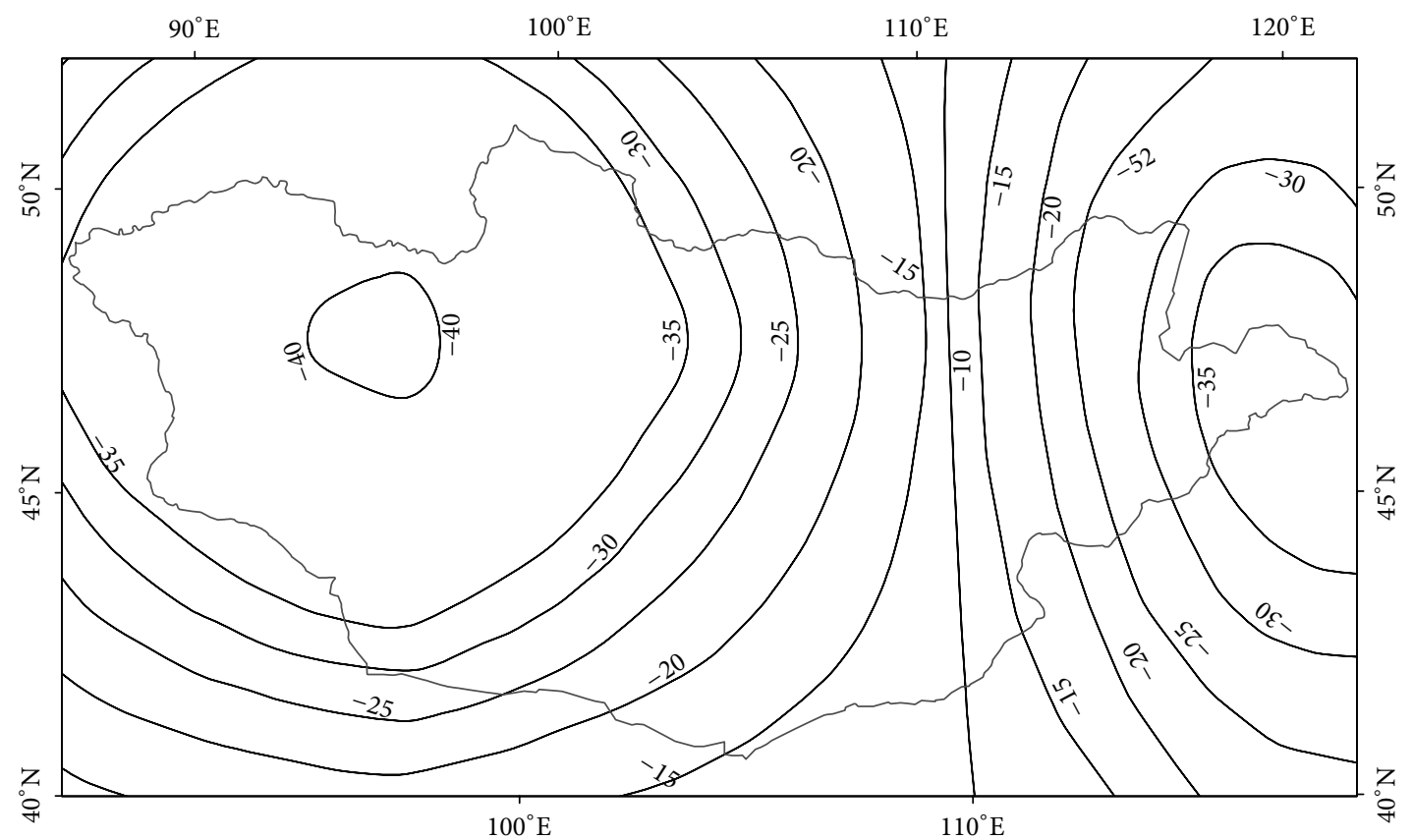

FIGURE 4: Effects of future grassland degradation on average annual precipitation between years 2010 and 2020 (measured in millimeters) in Mongolia.

those during 2010-2020. The grassland degradation will make the annual average precipitation decrease by $15 \mathrm{~mm}$ to $50 \mathrm{~mm}$; in most parts of Mongolia, there has been a decrease in the tendency of annual average precipitation from the eastern and western to the central areas; the minimum average annual precipitation is $15 \mathrm{~mm}$ (Figure 5). The most obvious decrease of annual average precipitation occurs at the northwestern and eastern parts of Mongolia, but in the central part the change is relatively slow. According to the grassland distribution of Mongolia in 2010, the areas in which the annual average precipitation changes the most happen to be the grassland degradation areas it shows that the expansion and degradation of the grassland; have a significant impact on the local precipitation.

\subsection{Effects on the Monthly Average Temperature and Precipi-} tation. The effects of grassland degradation on the monthly average temperature vary from month to month during 2010-2020 and 2040-2050. The simulated result indicated that the overall trends of the monthly average temperature in the above two periods are basically the same and have the obvious seasonal characteristics. Grassland degradation has a significant impact on the temperature in Mongolia; the change range of monthly average temperature is $0.025-$ $0.075^{\circ} \mathrm{C}$; compared to the baseline data of 2010 and 2040 , the monthly average temperature increases continually, and the rate of change increases first then decreases; the maximum change of monthly average temperature appears in July with $0.075^{\circ} \mathrm{C}$, the minimum change of the average temperature occurs in December and January, and the change range is between 0.025 to $0.03^{\circ} \mathrm{C}$ (Figure 6). The simulated result about monthly average temperature further confirmed the above results; grassland degradation would lead to higher temperature, and the more serious the degradation is the greater the temperature rising is.

The areas of cropland in Mongolia is large, owning to the drought; in the recent 10 years, there has been a sharp decrease of cropland areas from 1.3 million hectares to 0.9 million hectares in the 1990s. So the effects of degradation on the monthly average precipitation are more significant than that on the monthly average temperature. Overall, the change trends of the monthly average precipitation during 2010-2020 and 2040-2050 are basically the same and have the seasonal variation phenomenon; the simulated results show that the precipitation in summer is significantly higher than in winter and the range of monthly average precipitation variation is $-3 \mathrm{~mm}$ to $5 \mathrm{~mm}$ (Figure 7); it can be seen clearly that precipitation change is obvious in June-August; the monthly average precipitation in the three months is $3-5 \mathrm{~mm}$ higher than the baseline year, but in the other months the monthly average precipitation is lower than the baseline. It illustrates that grassland degradation has direct and indirect impact on the precipitation, which is directly related to the local agricultural production and income.

\section{Conclusion and Discussion}

This study analyzed the interaction effects between the grassland degradation and the climate change on the basis of the WRF model at the national levels and assessed the effects of grassland degradation on the annual and monthly average temperature and precipitation in Mongolia. Despite some limitations due to the spatial resolution of the data and long simulation time, the data are still helpful in assessing 


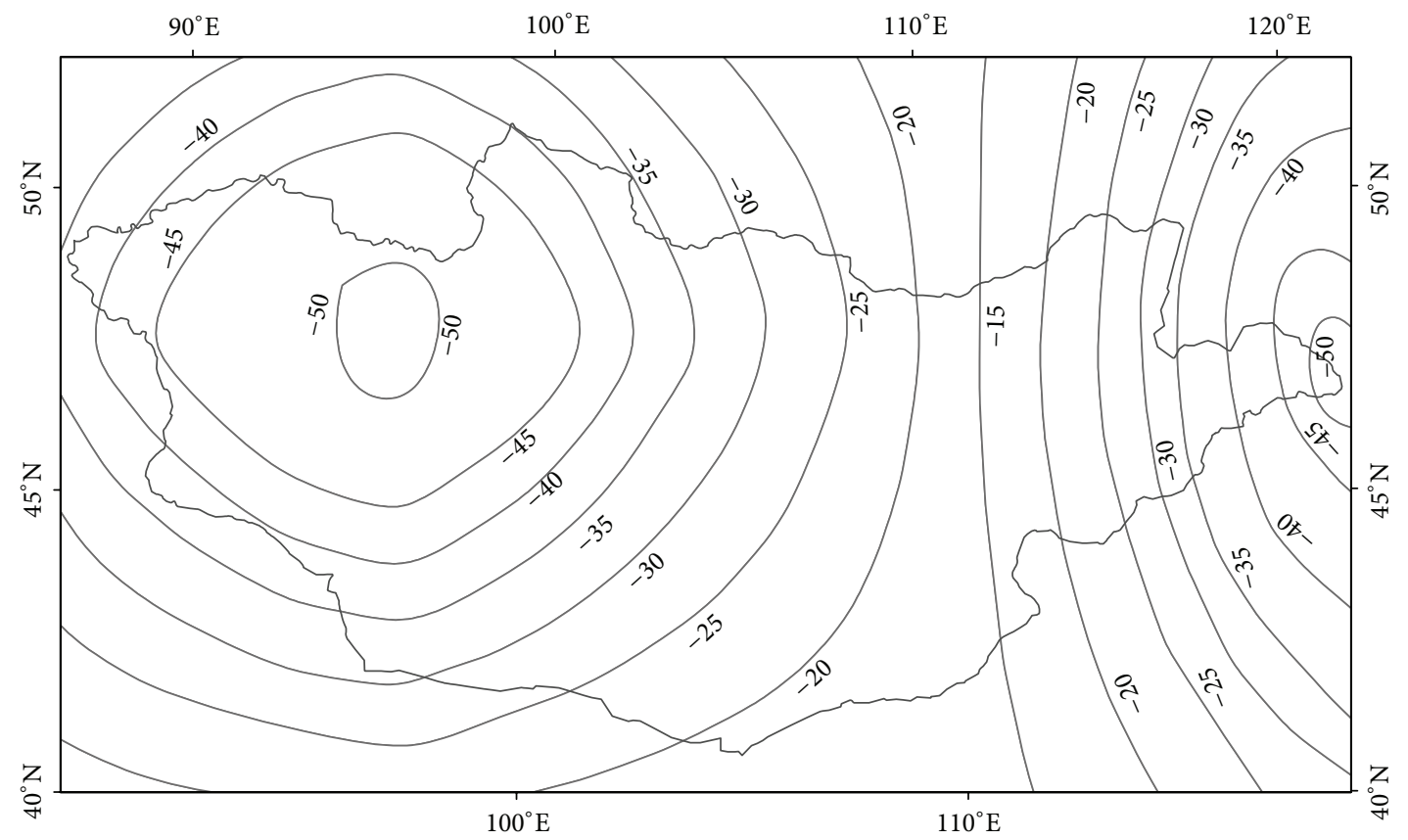

FIGURE 5: Effects of future grassland degradation on average annual precipitation between years 2040 and 2050 (measured in millimeters) in Mongolia.

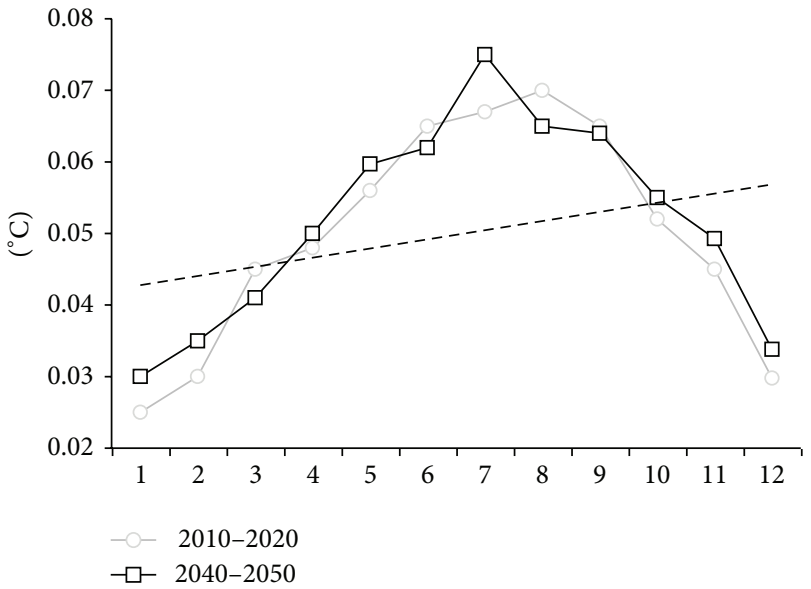

FIGURE 6: Effects of future grassland degradation on average monthly temperature during two decades (measured in degree Celsius) in Mongolia.

the impacts of the grassland degradation on the climate change. The results indicate that grassland degradation has an obvious effect on the regional temperature and precipitation in the next 40 years in Mongolia and the effects have spatial and temporal heterogeneity. Annual average temperature and precipitation change significantly from April to September; the maximum change is in July. The comparison between the simulated test and control test showed that, under the condition of grassland degradation, the areas in which the annual average temperature change obviously are mainly concentrated in the northwest, southeast, and middle-east

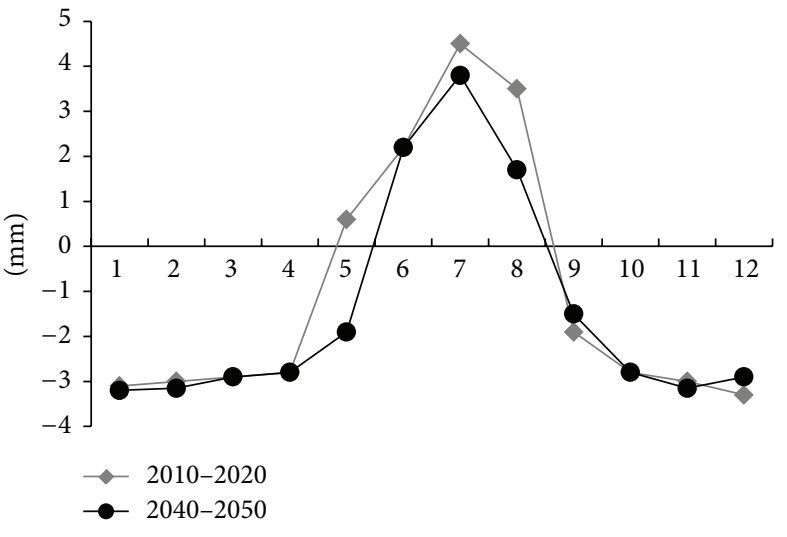

FIGURE 7: Effects of future grassland degradation on average monthly precipitation during two decades (measured in millimeters) in Mongolia.

of Mongolia, the annual average temperature change is approximately $-0.1^{\circ} \mathrm{C}-0.4^{\circ} \mathrm{C}$. In about $70 \%$ of areas in Mongolia; the annual average temperature change is $0.1^{\circ} \mathrm{C}-0.3^{\circ} \mathrm{C}$. Besides, annual average precipitation change in Mongolia has obviously regional and seasonal characteristics. Overall, there has been a falling trend of average annual precipitation change in most regions of Mongolia; the most significant changes are in July and August, and change values are 30$50 \mathrm{~mm}$. According to the analysis of the monthly average temperature and precipitation, the comparison between the simulated test and control test showed that in July and August the monthly average temperature rose most obviously; the change value is $0.06^{\circ} \mathrm{C}-0.075^{\circ} \mathrm{C}$. In winter the temperature 
rose relatively slow, with change value of about $0.02^{\circ} \mathrm{C}-0.03^{\circ} \mathrm{C}$. The most obvious change of monthly average precipitation is from April to September; the change value is $2-5 \mathrm{~mm}$.

The impact of grassland degradation on the climate change ought to be comprehensive; in this study we only consider the impact of grassland degradation on temperatures and precipitation, while, without report on the energy balance, circulation, monsoon, and other climate factors, this may lead to incomprehensive analysis of the impacts. And there are still some shortages in this study. Firstly, the climate effect could be caused by some other factors except for grassland degeneration, such as solar activity and other human activities, while only the grassland degeneration has been taken into account in this study, so more factors could be included in further research. Secondly, some uncertainties exist in the simulated test. The uncertainness may come from data, parameterization, and WRF model itself. So there is still further work to do in order to get more accurate results in the future research.

\section{Conflict of Interests}

The authors declare that there is no conflict of interests regarding the publication of this paper.

\section{Acknowledgments}

This research was supported by the Key Project funded by the Chinese Academy of Sciences (Grant no. KZZD-EW-08), National Key Programme for Developing Basic Science in China (Grant no. 2010CB950900), and the External Cooperation Program of the Chinese Academy of Sciences (no. GJHZ1312).

\section{References}

[1] V. Brovkin, A. Ganopolski, M. Claussen, C. Kubatzki, and V. Petoukhov, "Modelling climate response to historical land cover change," Global Ecology and Biogeography, vol. 8, no. 6, pp. 509517, 1999.

[2] J. A. Foley, R. DeFries, G. P. Asner et al., "Global consequences of land use," Science, vol. 309, no. 5734, pp. 570-574, 2005.

[3] R. Pachauri and A. Reisinger, IPCC Fourth Assessment Report, Intergovernmental Panel on Climate Change (IPCC), Geneva, Switzerland, 2007.

[4] J. J. Feddema, K. W. Oleson, G. B. Bonan et al., "Atmospheric science: the importance of land-cover change in simulating future climates," Science, vol. 310, no. 5754, pp. 1674-1678, 2005.

[5] X. Z. Deng, C. H. Zhao, and H. M. Yan, "Systematic modeling of impacts of land use and land cover changes on regional climate: a review," Advances in Meteorology, vol. 2013, Article ID 317678, 10 pages, 2013.

[6] R. A. Pielke Sr., G. Marland, R. A. Betts et al., "The influence of land-use change and landscape dynamics on the climate system: relevance to climate-change policy beyond the radiative effect of greenhouse gases," Philosophical Transactions of the Royal Society A, vol. 360, no. 1797, pp. 1705-1719, 2002.

[7] J. Hansen, M. Sato, R. Ruedy, K. Lo, D. W. Lea, and M. Medina-Elizade, "Global temperature change," Proceedings of the National Academy of Sciences of the United States of America, vol. 103, no. 39, pp. 14288-14293, 2006.

[8] X. Deng, J. Huang, E. Uchida, S. Rozelle, and J. Gibson, "Pressure cookers or pressure valves: do roads lead to deforestation in China?" Journal of Environmental Economics and Management, vol. 61, no. 1, pp. 79-94, 2011.

[9] H. Zhao, E. Uchida, X. Deng, and S. Rozelle, "Do trees grow with the economy? A spatial analysis of the determinants of forest cover change in Sichuan, China," Environmental and Resource Economics, vol. 50, no. 1, pp. 61-82, 2011.

[10] X. Deng, Q. Jiang, J. Zhan, S. He, and Y. Lin, "Simulation on the dynamics of forest area changes in Northeast China," Journal of Geographical Sciences, vol. 20, no. 4, pp. 495-509, 2010.

[11] X. Deng, Q. Jiang, H. Su, and F. Wu, "Trace forest conversions in Northeast China with a 1-km area percentage data model," Journal of Applied Remote Sensing, vol. 4, no. 1, Article ID 041893, 2010.

[12] X. Deng, J. Huang, Q. Huang, S. Rozelle, and J. Gibson, “Do roads lead to grassland degradation or restoration? A case study in Inner Mongolia, China," Environment and Development Economics, vol. 16, no. 6, pp. 751-773, 2011.

[13] F. Wu, X. Deng, F. Yin, and Y. Yuan, "Projected changes of grassland productivity along the representative concentration pathways during 2010-2050 in China," Advance in Meteorology, vol. 2013, Article ID 812723, 9 pages, 2013.

[14] Q. Jiang, X. Deng, H. Yan, D. Liu, and R. Qu, "Identification of food security in the mountainous guyuan prefecture of China by exploring changes of food production," Journal of Food, Agriculture and Environment, vol. 10, no. 1, pp. 210-216, 2012.

[15] Q. Jiang, X. Deng, J. Zhan, and S. He, "Estimation of land production and its response to cultivated land conversion in North China Plain," Chinese Geographical Science, vol. 21, no. 6, pp. 685-694, 2011.

[16] J. Li, X. Deng, and K. C. Seto, "Multi-level modeling of urban expansion and cultivated land conversion for urban hotspot counties in China," Landscape and Urban Planning, vol. 108, no. 2-4, pp. 131-139, 2012.

[17] X. Deng, J. Huang, S. Rozelle, and E. Uchida, "Growth, population and industrialization, and urban land expansion of China," Journal of Urban Economics, vol. 63, no. 1, pp. 96-115, 2008.

[18] X. Deng, J. Huang, S. Rozelle, and E. Uchida, "Economic growth and the expansion of urban land in China," Urban Studies, vol. 47, no. 4, pp. 813-843, 2010.

[19] J. Liu and X. Deng, "Influence of different land use on urban microenvironment in Beijing City, China," Journal of Food, Agriculture and Environment, vol. 9, no. 3-4, pp. 1005-1011, 2011.

[20] T. N. Chase, R. A. Pielke Sr., T. G. F. Kittel, R. R. Nemani, and S. W. Running, "Simulated impacts of historical land cover changes on global climate in northern winter," Climate Dynamics, vol. 16, no. 2-3, pp. 93-105, 2000.

[21] O. Jimmy, A. Roger, A. Pielke, J. Eastman, R. Mahmood, and G. Hubbard, "Impact of irrigation on midsummer surface fluxes and temperature under dry synoptic conditions: a regional atmospheric model study of the U.S. high plains," Monthly Weather Review, vol. 131, no. 3, pp. 556-564, 2003.

[22] N. S. Diffenbaugh, "Influence of modern land cover on the climate of the United States," Climate Dynamics, vol. 33, no. 7-8, pp. 945-958, 2009.

[23] Y. Hu, W. Dong, and Y. He, "Impact of land surface forcings on mean and extreme temperature in eastern China," Journal of Geophysical Research D, vol. 115, no. D19, article 16, 2010. 
[24] N. Christidis, A. Stott, C. Heger, and A. Betts, “The role of land use change in the recent warming of daily extreme temperatures," Geophysical Research Letters, vol. 40, no. 3, pp. 589-594, 2013.

[25] R. Avissar and D. Werth, "Global hydroclimatological teleconnections resulting from tropical deforestation," Journal of Hydrometeorology, vol. 6, no. 2, pp. 134-145, 2005.

[26] G. B. Bonan, "Forests and climate change: forcings, feedbacks, and the climate benefits of forests," Science, vol. 320, no. 5882, pp. 1444-1449, 2008.

[27] F. B. Avila, A. J. Pitman, M. G. Donat, L. V. Alexander, and G. Abramowitz, "Climate model simulated changes in temperature extremes due to land cover change," Journal of Geophysical Research D, vol. 117, no. D4, pp. 108-126, 2012.

[28] G. P. Asner, A. J. Elmore, L. P. Olander, R. E. Martin, and T. Harris, "Grazing systems, ecosystem responses, and global change," Annual Review of Environment and Resources, vol. 29, pp. 261-299, 2004.

[29] F. Wu, X. Deng, F. Yin, and Y. Yuan, "Projected changes of grassland productivity along the representative concentration pathways during 2010-2050 in China," Advance in Meteorology, vol. 2013, Article ID 812723, 9 pages, 2013.

[30] V. K. Arora and A. Montenegro, "Small temperature benefits provided by realistic afforestation efforts," Nature Geoscience, vol. 4, no. 8, pp. 514-518, 2011.

[31] A. M. Degu, F. Hossain, D. Niyogi et al., "The influence of large dams on surrounding climate and precipitation patterns," Geophysical Research Letters, vol. 38, no. 4, Article ID L04405, 2011.

[32] A. T. Woldemichael, F. Hossain, and R. Pielke, "Understanding the impact of dam-triggered land use/land cover change on the modification of extreme precipitation," Water Resources Research, vol. 48, no. 9, pp. 1-16, 2012.

[33] А. Хауленбек, The Present Situation of Desertification Mongolia, Ulaanbaatar, Mongolia, 2009.

[34] C. Humphrey, "Pastoral nomadism in Mongolia: the role of herdsmen's cooperatives in the national economy," Development and Change, vol. 9, no. 1, pp. 133-160, 1978.

[35] M. A. Zhang, E. Borjigin, and H. Zhang, "Mongolian nomadic culture and ecological culture: on the ecological reconstruction in the agro-pastoral mosaic zone in Northern China," Ecological Economics, vol. 62, no. 1, pp. 19-26, 2007.

[36] A. Yatagai and T. Yasunari, "Trends and decadal-scale fluctuations of surface air temperature over China and Mongolia during the recent 40 year period (1951-1990)," Journal of the Meteorological Society of Japan, vol. 72, no. 6, pp. 937-957, 1994.

[37] N. N. Barger, D. S. Ojima, J. Belnap, W. Shiping, W. Yanfen, and Z. Chen, "Changes in plant functional groups, litter quality, and soil carbon and nitrogen mineralization with sheep grazing in an Inner Mongolian Grassland," Rangeland Ecology \& Management, vol. 57, no. 6, pp. 613-619, 2004.

[38] Y. Xue, "The impact of desertification in the Mongolian and the Inner Mongolian grassland on the regional climate," Journal of Climate, vol. 9, no. 9, pp. 2173-2189, 1996.

[39] R. A. Pielke, A. Pitman, D. Niyogi et al., "Land use/land cover changes and climate: modeling analysis and observational evidence," Wiley Interdisciplinary Reviews, vol. 2, no. 6, pp. 828850, 2011.

[40] L. Ruby Leung and Y. Qian, "Atmospheric rivers induced heavy precipitation and flooding in the western U.S. simulated by the WRF regional climate model," Geophysical Research Letters, vol. 36, no. 3, pp. 3820-3825, 2009. 

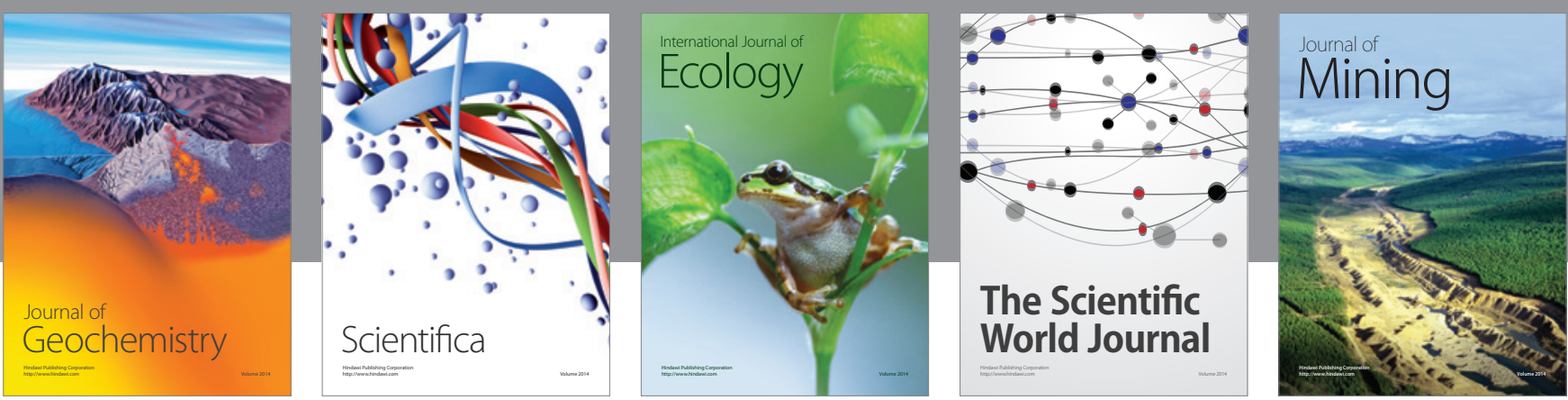

The Scientific World Journal
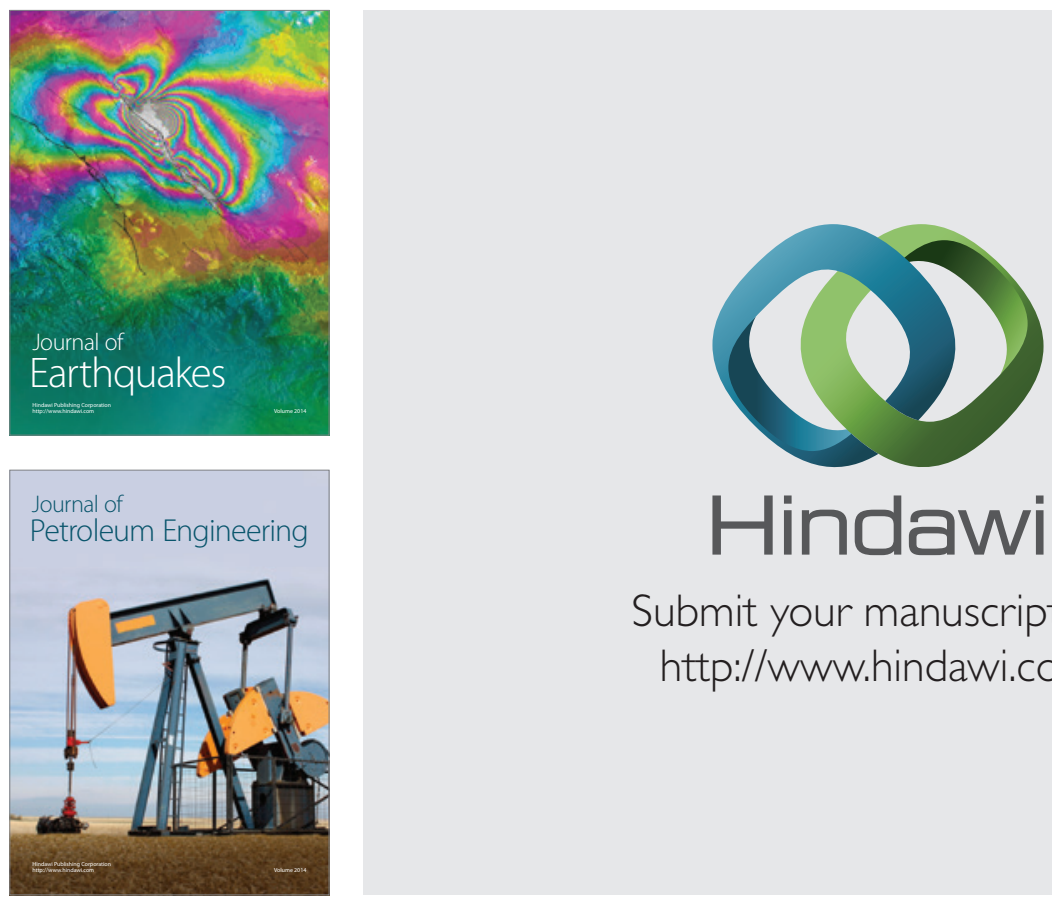

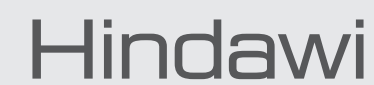

Submit your manuscripts at

http://www.hindawi.com
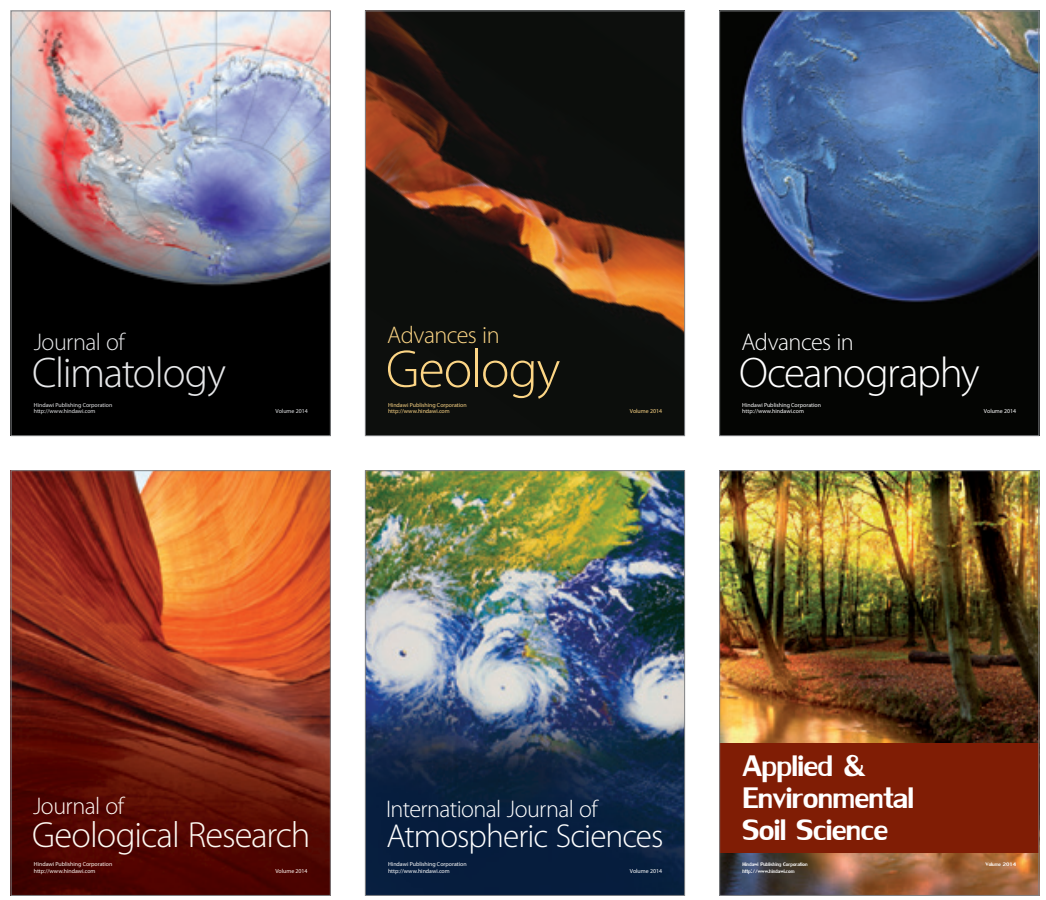
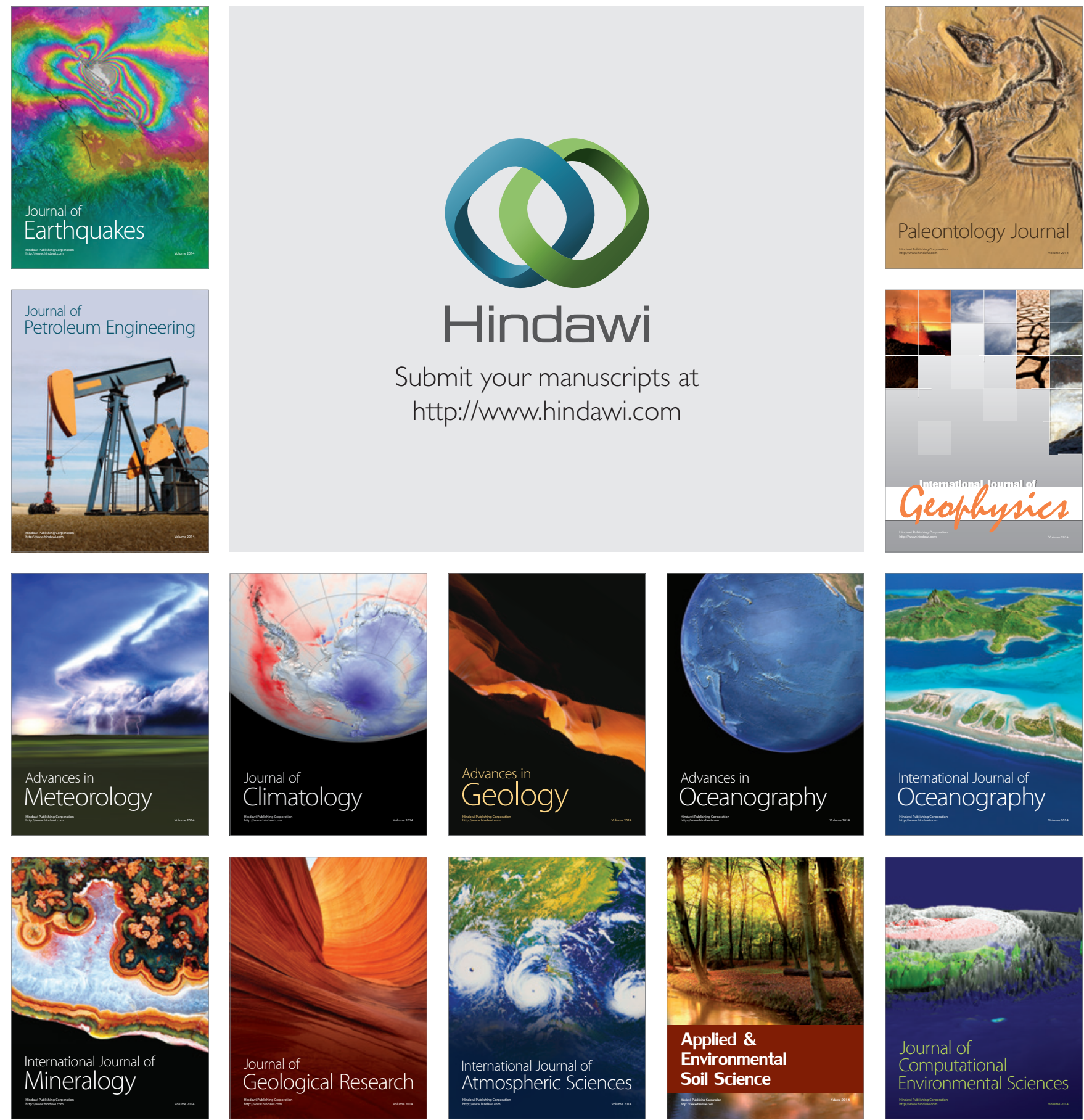